\title{
The gene expression profile induced by Wnt 3a in NIH 3 T3 fibroblasts
}

\author{
Shaoqiong Chen • Sarah McLean • David E. Carter • \\ Andrew Leask
}

Received: 7 November 2007 / Accepted: 19 December 2007 / Published online: 20 January 2008

(C) The International CCN Society 2007

\begin{abstract}
Wnt proteins play important roles in regulating cell differentiation, proliferation and polarity. Wnts have been proposed to play roles in tissue repair and fibrosis, yet the gene expression profile of fibroblasts exposed to Wnts has not been examined. We use Affymetrix genome-wide expression profiling to show that a 6-h treatment of fibroblasts of Wnt3a results in the induction of mRNAs encoding known Wnt targets such as the fibrogenic pro-adhesive molecule connective tissue growth factor (CTGF, CCN2). Wnt3a also induces mRNAs encoding potent pro-fibrotic proteins such as TGF $\beta$ and endothelin-1 (ET-1). Moreover, Wnt3a promotes genes associated with cell adhesion and migration, vasculature development, cell proliferation and Wnt signaling. Conversely, Wnt3a suppresses gene associated with skeletal development, matrix degradation and cell death. Results were confirmed using real-time polymerase chain reaction of cells exposed to Wnt3a and Wnt10b. These results suggest that Wnts induce genes promoting fibroblast differentiation towards angiogenesis and matrix remodeling, at the expense of skeletal development.
\end{abstract}

Keywords CCN2 $\cdot$ Microarray $\cdot$ Fibroblasts

\section{Introduction}

Wnt signaling, a conserved molecular mechanism in animals, enables cells to converse with each other to co-

S. Chen · S. McLean · D. E. Carter · A. Leask $(\bowtie)$

CIHR Group in Skeletal Development and Remodeling,

Division of Oral Biology and Department of Physiology

and Pharmacology, Schulich School of Medicine and Dentistry,

University of Western Ontario,

Dental Sciences Building,

London, ON, Canada N6A 5C1

e-mail: Andrew.Leask@schulich.uwo.ca ordinate a remarkable variety of cellular processes, such as cell fate, differentiation, cell survival and migration during morphogenesis (Logan and Nusse 2004). Wnts can stimulate numerous intracellular signal transduction cascades, including the essentially linear canonical $\beta$-catenin pathway, which regulates gene expression, and non-canonical pathways, which regulate many other aspects of cell biology (Cadigan and Liu 2006). A hallmark of the canonical Wnt pathway is the stabilization and nuclear localization of $\beta$-catenin (Schohl and Fagotto 2002). Without the presence of Wnts, $\beta$-catenin is targeted for degradation, whereas the presence of Wnts results in $\beta$ catenin stabilization and nuclear localization (Willert and Jones 2006). There are several different Wnt proteins, often with different overall effects on cells (Musgrove 2004).

Wnt signaling has been shown to play an essential role in brain, limb, mammary, skin, and most recently cardiovascular and lung development (Morrisey 2003). Chilosi and colleagues (2003) observed accumulation of nuclear $\beta$ catenin, the downstream mediator of the canonical Wnt pathway, in both epithelial and mesenchymal (myofibroblast) cell lineages in adult human lung and evidence of activation of this pathway in idiopathic pulmonary fibrosis. In this light, it has been suggested that fibroblasts isolated from fibrotic lesions of scleroderma patients possess a socalled 'Wnt-signature' (Gardner et al. 2006). However, it is unclear what exactly a 'Wnt signature' is in fibroblasts, nor if application of Wnts to fibroblasts result in the direct activation a fibrogenic or tissue repair program in fibroblasts. Wnts, in particular Wnt 3a, is however known to induce the expression of members of the $\mathrm{CCN}$ family of proteins [including CTGF (CCN2) and cyr61 (CCN1)] in mesenchymal cells (Luo et al. 2004; Si et al. 2006; Leask and Abraham 2006). CCN proteins play key roles in matrix remodeling, tissue repair and fibrogenesis (Leask and 
Table 1 Cluster analysis $(p<0.02)$ of mRNAs (out of 145 total) induced more than twofold in fibroblasts by Wnt3a treatment $(6 \mathrm{~h})$

\begin{tabular}{|c|c|c|c|}
\hline Affymetrix ID & Increase & Gene name & \\
\hline \multicolumn{4}{|l|}{ Cell cycle } \\
\hline 1416268_at & 2.266 & Ets2 & E26 avian leukemia oncogene 2 \\
\hline 1422631_at & 7.433 & Ahr & Aryl-hydrocarbon receptor \\
\hline 1424325_at & 2.098 & Esco1 & Establishment of cohesion 1 homolog 1 \\
\hline 1423250_a_at & 3.321 & Tgfb2 & TGFbeta2 \\
\hline 1427267_at & 2.098 & Zfp469 & Zinc finger protein 469 \\
\hline 1429658_a_at & 2.15 & Smc2 & Structural maintenance of chromosomes 2 \\
\hline 1439766_x_at & 3.715 & Vegfc & Vascular endothelial growth factor C \\
\hline 1440739_at & 3.275 & Vegfc & Vascular endothelial growth factor C \\
\hline 1449027_at & 2.54 & Rhou & Ras homolog gene family, member $U$ \\
\hline 1449028_at & 3.193 & Rhou & Ras homolog gene family, member $U$ \\
\hline 1450922_a_at & 3.483 & Tgfb2 & TGFbeta2 \\
\hline 1450923_at & 3.086 & Tgfb2 & TGFbeta2 \\
\hline 1452459_at & 2.837 & Aspm & Abnormal spindle-like, microcephaly associated \\
\hline 1453851_a_at & 4.925 & Gadd $45 \mathrm{~g}$ & Growth arrest and DNA-damage-inducible 45 gamma \\
\hline \multicolumn{4}{|l|}{ Angiogenesis } \\
\hline 1416039_x_at & 3.067 & CCN1(Cyr61) & Cysteine-rich protein 61 \\
\hline 1419417_at & 3.372 & Vegfc & Vascular endothelial growth factor $\mathrm{C}$ \\
\hline 1423250_a_at & 3.321 & $\operatorname{Tgfb} 2$ & TGFbeta2 \\
\hline 1434025_at & 2.145 & K1f5 & Kruppel-like factor 5 \\
\hline 1434776_at & 2.154 & Sema5a & Semaphorin $5 \mathrm{~A}$ \\
\hline 1438133_a_at & 3.229 & CCN1(Cyr61) & Cysteine rich protein 61 \\
\hline 1439766_x_at & 3.715 & Vegfc & Vascular endothelial growth factor $\mathrm{C}$ \\
\hline 1440739_at & 3.275 & Vegfc & Vascular endothelial growth factor $\mathrm{C}$ \\
\hline 1442340_x_at & 3.186 & CCN1(Cyr61) & Cyr61 \\
\hline 1450922_a_at & 3.483 & $\operatorname{Tgfb} 2$ & TGFbeta2 \\
\hline 1450923_at & 3.086 & Tgfb2 & TGFbeta2 \\
\hline 1451021_a_at & 2.227 & K1f5 & Kruppel-like factor 5 \\
\hline 1451924_a_at & 2.113 & Edn 1 & Endothelin 1 \\
\hline 1457823_at & 2.908 & Cyr61 & Cyr61 \\
\hline \multicolumn{4}{|l|}{ Cytoskeleton } \\
\hline 1417011_at & 2.017 & $\mathrm{Sdc} 2$ & Syndecan 2 \\
\hline 1425060_s_at & 3.794 & Rsn & Restin \\
\hline 1428579_at & 2.38 & Fmnl2 & Formin-like 2 \\
\hline 1431098_at & 2.668 & Clip1 & CAP-GLY domain containing linker protein 1 \\
\hline 1435551_at & 5.084 & Fhod3 & Formin homology 2 domain containing 3 \\
\hline 1437554_at & 2.382 & Plec1 & Plectin 1 \\
\hline 1450650_at & 2.356 & Myo10 & Myosin X \\
\hline 1455056_at & 2.645 & Lmo7 & LIM domain only 7 \\
\hline \multicolumn{4}{|c|}{ Cell motility/adhesion } \\
\hline 1418733_at & 2.436 & Twist1 & Twist gene homolog 1 \\
\hline 1423250_a_at & 3.321 & $\operatorname{Tgfb} 2$ & TGFbeta2 \\
\hline 1426300_at & 2.559 & Alcam & Activated leukocyte cell adhesion molecule \\
\hline 1426301_at & 2.572 & Alcam & Activated leukocyte cell adhesion molecule \\
\hline 1427267_at & 2.098 & Zfp469 & Zinc finger protein 469 \\
\hline 1437466_at & 2.865 & Alcam & Activated leukocyte cell adhesion molecule \\
\hline 1434776_at & 2.154 & Sema5a & Semaphorin $5 \mathrm{~A}$ \\
\hline 1437467_at & 2.846 & Alcam & Activated leukocyte cell adhesion molecule \\
\hline 1450922_a_at & 3.483 & Tgfb2 & TGFbeta1 \\
\hline 1450923_at & 3.086 & Tgfb2 & TGFbeta2 \\
\hline 1454966_at & 2.161 & Itga8 & Integrin alpha 8 \\
\hline \multicolumn{4}{|l|}{ Wnt signaling } \\
\hline 1428808_at & 2.016 & Prickle2 & Prickle-like 2 \\
\hline 1450044_at & 2.687 & Fzd7 & Frizzled homolog 7 \\
\hline 1450772_at & 2.195 & Wnt11 & Wingless-related MMTV integration site 11 \\
\hline 1459804_at & 2.105 & Crebbp & CREB binding protein \\
\hline
\end{tabular}


Table 1 (continued)

\begin{tabular}{llll}
\hline Affymetrix ID & Increase & Gene name & \\
\hline 1459804_at & 2.105 & Crebbp & CREB binding protein \\
1460729_at & 2.606 & Rock1 & Rho-associated coiled-coil containing protein kinase 1 \\
CCN family & 3.229 & CCN1(Cyr61) & \\
1438133_a_at & 3.186 & CCN1(Cyr61) & Cysteine rich protein 61 \\
1442340_x_at & 2.908 & CCN1(Cyr61) & Cysteine rich protein 61 \\
1457823_at & 2.42 & CCN2 $($ Ctgf) & Cysteine rich protein 61 \\
1416953_at & 2.232 & CCN4(Wisp1) & Connective tissue growth factor \\
1448593_at & 3.661 & CCN5(Wisp2) & WNT1 inducible signaling pathway protein 1 \\
1419015_at & 3.023 & CCN4(Wisp1) & WNT1 inducible signaling pathway protein 2 \\
1448594_at & & & WNT1 inducible signaling pathway protein 1 \\
\hline
\end{tabular}

Abraham 2006). Although these results suggest that Wnts play key roles in initiating tissue remodeling and fibrotic expression profiles in fibroblasts, this hypothesis has not been tested. In fact, the overall effect of Wnts on fibroblast gene expression is wholly unknown.

In this report, we use Affymetrix gene profiling and realtime polymerase chain reaction (PCR) analysis to identify the transcripts induced by Wnts in NIH $3 \mathrm{~T} 3$ fibroblasts. Our results provide new insights into the role that Wnts may play in fibroblast differentiation.

\section{Materials and methods}

Cell cultures NIH 3 T3 fibroblasts (ATCC) were cultured in low glucose Dulbecco's modified Eagle's medium (DMEM), 10\% calf serum, and antibiotic/antimycotic solution (Invitrogen, Burlington, Ontario) at $37^{\circ} \mathrm{C}, 5 \%$ $\mathrm{CO}_{2}$. Cells were serum starved in DMEM/0.5\% calf serum for $18 \mathrm{~h}$ and treated with or without Wnt3a (R and D Systems) for additional lengths of time as indicated. Alternatively, conditioned media obtained from cell lines overexpressing Wnt $1,4,5$ or 10 or containing empty expression vector (courtesy Cun-Yu Wang, University of Michigan) was added to DMEM/0.5\% calf serum in a $1: 1$ ratio. RNA was then harvested using Trizol (Invitrogen) and quantified as previously described (Shi-wen et al. 2004, 2006; Kennedy et al. 2007).

RNA quality assessment, probe preparation and gene chip hybridization and analysis

Microarrays and analysis were performed essentially as previously described (Shi-wen et al. 2004; Liu et al. 2007; Kennedy et al. 2007). All Gene Chips were processed at the London Regional Genomics Centre (Robarts Research Institute, London, ON; http:/www.lrgc.ca). RNA was harvested (Trizol, Invitrogen), quantified and quality
(RNA degradation and DNA contamination) was assessed using the Agilent 2100 Bioanalyzer (Agilent, Palo Alto, CA) and the RNA 6000 Nano kit (Caliper Life Sciences, Mountain View, CA). Quality data was then analyzed using the Degradometer (http://www.dnaarrays.org). Biotinylated complimentary RNA (cRNA) was prepared from $10 \mu \mathrm{g}$ of total RNA as per the Affymetrix GeneChip Technical Analysis Manual (Affymetrix, Santa Clara, CA). Doublestranded cDNA was synthesized using SuperScript II (Invitrogen) and oligo(dT) 24 primers. Biotin-labeled cRNA was prepared by cDNA in vitro transcription using the Bizarre High-Yield RNA Transcript Labeling kit (Enzo Brioche, New York, NY) incorporating biotinylated UTP and CTP. Fifteen $\mu \mathrm{g}$ of labeled cRNA was hybridized to Mouse Genome 4302.0 Gene Chips for $16 \mathrm{~h}$ at $45^{\circ} \mathrm{C}$ as described in the Affymetrix Technical Analysis Manual (Affymetrix, Santa Clara, CA). Gene Chips were stained with streptavidin-phycoerythrin, followed by an antibody solution and a second streptavidin-phycoerythrin solution, with all liquid handling performed by a GeneChip Fluidics Station 450 (Affymetrix). Gene Chips were scanned with the Affymetrix GeneChip Scanner 3000 (Affymetrix). Signal intensities for genes were generated using GCOS1.2 (Affymetrix) using default values for the Statistical Expression algorithm parameters and a target signal of 150 for all probe sets and a normalization value of 1 . Normalization was performed in GeneSpring 7.2 (Agilent Technologies Inc.). The RMA preprocessor was used to import data from the.cel files. Data were first transformed, (measurements less than 0.01 set to 0.01 ) and then normalized per chip to the 50th percentile, and per gene to wild-type control samples. Experiments were performed twice, and fold changes were identified using the GeneSpring filter. Data presented in Table 1 are an average of these independent studies. The fold change between treated and untreated samples had to be at least twofold to identify a transcript as being altered. These criteria had to be met in both sets of experiments. A list of the two fold changes was compiled and exported into EASE for further analysis. These group- 
Table 2 Cluster analysis $(p<0.02)$ of mRNAs (out of 159 total) decreased more than twofold in fibroblasts by Wnt3a treatment $(6 \mathrm{~h})$

\begin{tabular}{|c|c|c|c|}
\hline Affymetrix ID & Fold decrease & Gene name & \\
\hline \multicolumn{4}{|c|}{ Skeletal development } \\
\hline 1418175_at & 0.365 & Nr1i1 & Vitamin D receptor \\
\hline 1418176_at & 0.27 & Nr1i1 & Vitamin D receptor \\
\hline 1421073_a_at & 0.386 & EP4 & Prostaglandin E receptor 4 (subtype EP4) \\
\hline 1421979_at & 0.33 & HPDR & Phosphate regulating gene (hypophosphatemia) \\
\hline 1423500_a_at & 0.33 & Sox 5 & SRY-box containing gene 5 \\
\hline 1424950_at & 0.206 & $\operatorname{sox} 9$ & SRY-box containing gene 9 \\
\hline 1427277_at & 0.16 & Kitl & Transcribed locus \\
\hline 1439753_x_at & 0.412 & Six 4 & Sine oculis-related homeobox 4 homolog \\
\hline 1440827_x_at & 0.442 & Sox 5 & SRY-box containing gene 5 \\
\hline 1451538_at & 0.437 & Sox9 & SRY-box containing gene 9 \\
\hline 1456862_at & 0.415 & Six 4 & Sine oculis-related homeobox 4 homolog \\
\hline \multicolumn{4}{|c|}{ Endopeptidase activity } \\
\hline 1417109_at & 0.444 & Tinagl & Tubulointerstitial nephritis antigen-like \\
\hline 1422561_at & 0.457 & Adamts5 & Aggrecanase-2 \\
\hline 1433434_at & 0.468 & AW551984 & Expressed sequence AW551984 \\
\hline 1437506_at & 0.458 & Adamts6 & A disintegrin-like and metallopeptidase with thrombospondin type 1 motif, 6 \\
\hline 1435697_a_at & 0.455 & Mmp12 & Matrix metalloprotenase 12 \\
\hline 1450716_at & 0.426 & Adamts1 & A disintegrin-like and metallopeptidase with thrombospondin type 1 motif, 1 \\
\hline 1450658_at & 0.416 & Adamts5 & Aggrecanase-2 \\
\hline 1418981_at & 0.44 & Casp12 & Caspase 12 \\
\hline 1421979_at & 0.33 & Phex & Phosphate regulating gene (hypophosphatemia) \\
\hline \multicolumn{4}{|c|}{ Programmed cell death } \\
\hline 1415832_at & 0.417 & Agtr2 & Angiotensin II receptor, type 2 \\
\hline 1417130_s_at & 0.452 & Angpt14 & Angiopoietin-like 4 \\
\hline 1418981_at & 0.44 & Casp12 & Caspase 12 \\
\hline $1424950 \_$at & 0.206 & Sox9 & SRY-box containing gene 9 \\
\hline 1426752_at & 0.477 & Phf17 & PHD finger protein 17 \\
\hline 1434601_at & 0.498 & Amigo2 & Adhesion molecule with Ig like domain 2 \\
\hline 1442884_at & 0.349 & Hgf & Hepatocyte growth factor \\
\hline 1449297_at & 0.446 & Casp12 & Caspase 12 \\
\hline 1449033_at & 0.397 & Tnfrsfl1b & Tumor necrosis factor receptor superfamily, member $11 \mathrm{~b}$ (osteoprotegerin) \\
\hline 1451538 at & 0.437 & Sox 9 & SRY-box containing gene 9 \\
\hline 1451866_a_at & 0.445 & Hgf & Hepatocyte growth factor \\
\hline 1452179_at & 0.423 & Phf17 & PHD finger protein 17 \\
\hline 1452985_at & 0.452 & Uaca & Uveal autoantigen with coiled-coil domains and ankyrin repeats \\
\hline \multicolumn{4}{|l|}{ Transcription } \\
\hline 1418175_at & 0.365 & Nr1i1 & Vitamin D receptor \\
\hline 1418176 at & 0.27 & Nr1i1 & Vitamin D receptor \\
\hline 1422607_at & 0.425 & Etv1 & Ets variant gene 1 \\
\hline 1423233 at & 0.388 & Cebpd & CCAAT/enhancer binding protein (C/EBP), delta \\
\hline 1427277_at & 0.16 & Kitl & Kit1 \\
\hline 1434736_at & 0.416 & Hlf & Hepatic leukemia factor \\
\hline 1435828 at & 0.332 & Maf & Musculoaponeurotic fibrosarcoma (v-maf) \\
\hline 1456862_at & 0.415 & Six 4 & Sine oculis-related homeobox 4 homolog \\
\hline 1439753_x_at & 0.412 & Six 4 & Sine oculis-related homeobox 4 homolog \\
\hline 1447849_s_at & 0.339 & Maf & Musculoaponeurotic fibrosarcoma (v-maf) \\
\hline 1450684_at & 0.356 & Etv1 & Ets variant gene 1 \\
\hline 1456060_at & 0.301 & Maf & Musculoaponeurotic fibrosarcoma (v-maf) \\
\hline 1416302_at & 0.388 & Ebf1 & Early B-cell factor 1 \\
\hline 1416301_a_at & 0.493 & Ebf1 & Early B-cell factor 1 \\
\hline 1439789_at & 0.481 & Ebf1 & Early B-cell factor 1 \\
\hline 1428349_s_at & 0.432 & Ebf3 & Early B-cell factor 3 \\
\hline 1440827_x_at & 0.442 & Sox 5 & SRY-box containing gene 5 \\
\hline 1451538_at & 0.437 & Sox9 & SRY-box containing gene 9 \\
\hline
\end{tabular}


Table 2 (continued)

\begin{tabular}{llll}
\hline Affymetrix ID & Fold decrease & Gene name & \\
\hline 1423500_a_at & 0.33 & Sox5 & SRY-box containing gene 5 \\
1424950_at & 0.206 & Sox9 & SRY-box containing gene 9 \\
G protein coupled receptor signaling & & Angiotensin II receptor, type 2 \\
1415832_at & 0.417 & Agtr2 & Chemokine (C-X-C motif) receptor 7 \\
1417625_s_at & 0.282 & Cxcr7 & Prostaglandin F receptor \\
1420349_at & 0.137 & Ptgfr & Prostaglandin E receptor 4 (subtype EP4) \\
1421073_a_at & 0.386 & Ptger4 & Gastrin releasing peptide receptor \\
1421470_at & 0.395 & Grpr & Calcitonin receptor-like \\
1425814_a_at & 0.223 & Calcrl & Prostaglandin F receptor \\
1440777_x_at & 0.334 & Ptgfr & Prostaglandin F receptor \\
1449828_at & 0.375 & Ptgfr & Prostaglandin F receptor \\
1453924_a_at & 0.16 & Ptgfr & G protein-coupled receptor 149 \\
1456858_at & 0.385 & & \\
\hline
\end{tabular}

ings were restricted to the GO Biological Process and subjected to Fisher exact probability and Benjamini as the primary statistics and multiplicity correction respectively. These groupings had to have at least six members/ functional groupings that were part of the GO Biological Process system $(p<0.02)$ to be considered relevant. Note that the list of $\mathrm{CCN}$ family members was compiled independent of the cluster analysis. The relevant lists were exported back into the affymetrix.com website to compile the gene name and functions.

Real time RT-PCR RNA was harvested using the Qiashredder and RNeasy kit (Qiagen) and used for real-time RT-PCR. Twenty-five nanograms of RNA was reverse transcribed and

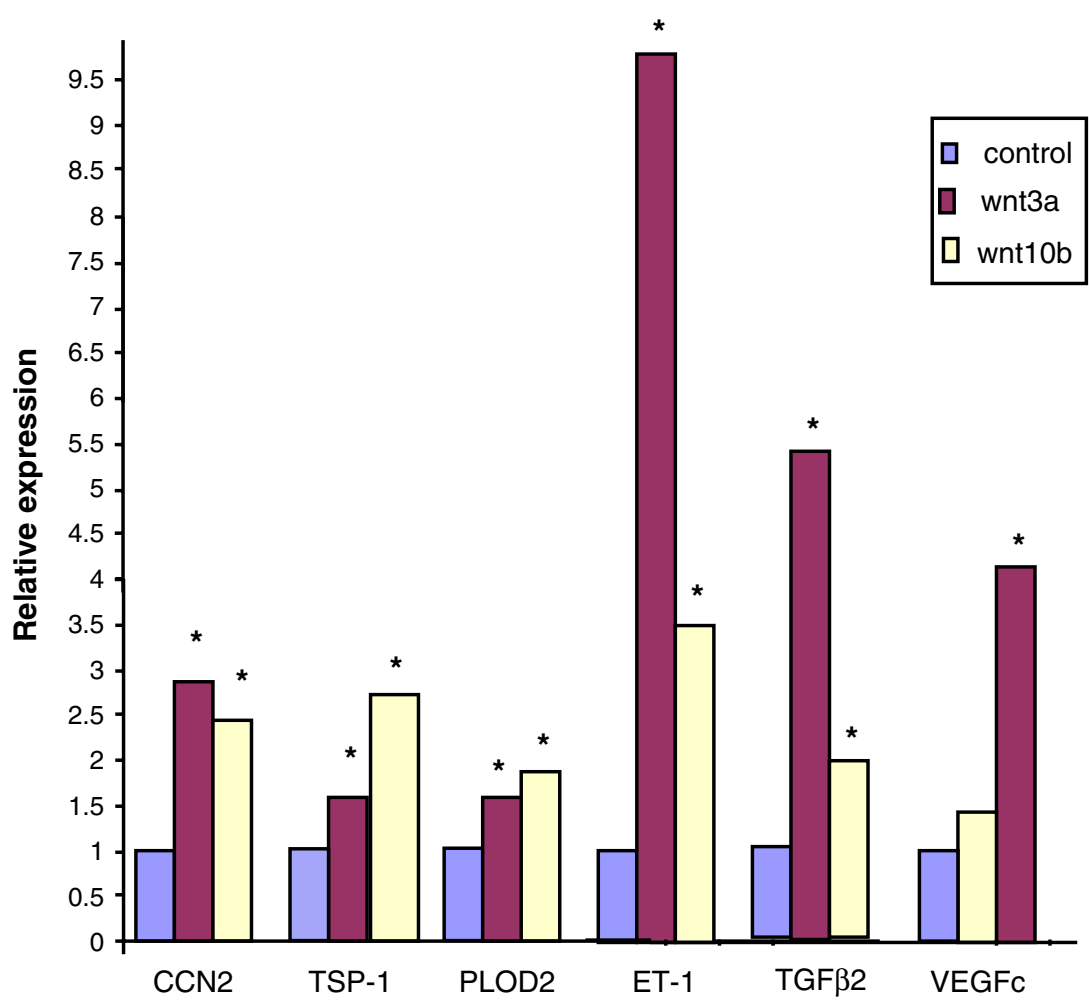

Fig. 1 Wnts $3 \mathrm{a}$ and $10 \mathrm{~b}$ induce gene expression in fibroblasts. Wnt3a induces mRNA expression in fibroblasts. NIH 3T3 fibroblasts were treated with or without Wnt3a $(150 \mathrm{ng} / \mathrm{ml}, 6 \mathrm{~h})$. RNAs were harvested, and subjected to real time PCR analysis to detect $18 \mathrm{~S}$ rRNA and RNAs as indicated. Experiments were performed thrice. A representative experiment is shown (three replicates). Variation within samples was less than $10 \%$. NIH $3 \mathrm{~T} 3$ fibroblasts were also treated with or without conditioned media prepared from cells stably transfected with

empty expression vector or vector encoding Wnt10b. RNAs were harvested, and subjected to real time PCR analysis to detect $18 \mathrm{~S}$ rRNA and RNAs as indicated. Untreated or vector-alone-treated samples are expressed as 1 (control). Experiments were performed at least twice. A representative experiment is shown (three replicates). CCN2, TSP-1 (thrombospondin-1), VEGF-C, PLOD2, TGF $\beta 2$ and ET-1 transcripts were examined. Variation within samples was less than $10 \%$. Significance is indicated by an asterisk 

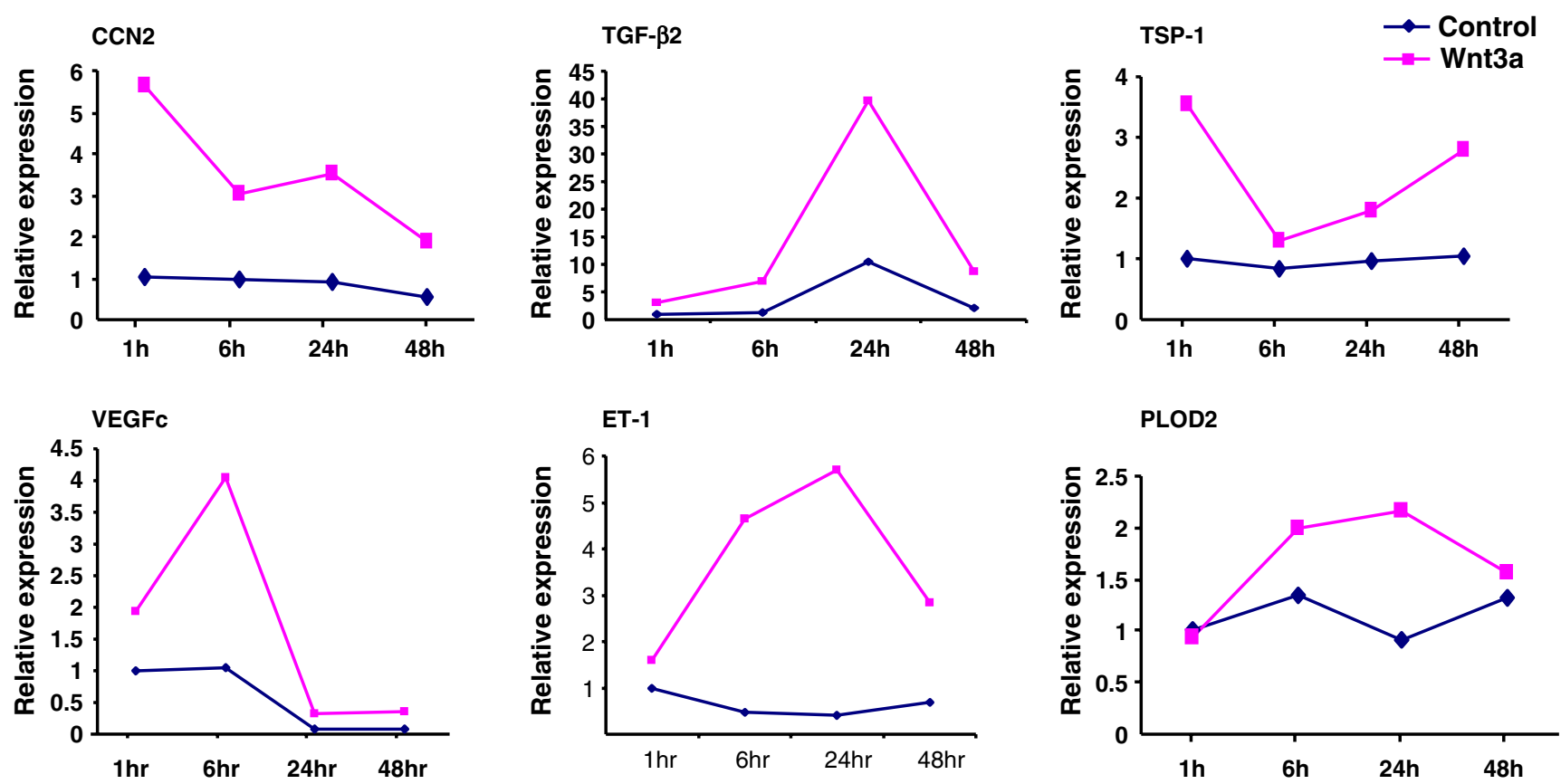

Fig. 2 Wnt $3 \mathrm{a}$ induces gene expression in fibroblasts. Time-course analysis. NIH 3T3 fibroblasts were treated with or without Wnt3a $(150 \mathrm{ng} / \mathrm{ml})$ for the time periods as indicated. RNAs were harvested, and subjected to real time PCR analysis to detect $18 \mathrm{~S}$ rRNA and target

RNAs as indicated. Experiments were performed twice. A representative experiment is shown (three replicates). CCN2, TSP-1 (thrombospondin-1), VEGF-C, PLOD2, TGF $\beta 2$ and ET-1 transcripts were examined. Variation within samples was less than $10 \%$

amplified using TaqMan Assays on Demand (Applied Biosystems) in a $15-\mu \mathrm{l}$ reaction containing primers (Assays on Demand, Applied Biosystems) and 6-carboxyfluroscein labeled TaqMan MGB probe. Reverse transcriptase qPCR Mastermix (Applied Biosystems) was added to samples and the ABI Prism 7900 HT sequence detector (Perkin-ElmerCetus, Vaudreuil, QC) was used according to manufacturer's instructions to detect amplified sequences. Samples were run in triplicate, transcripts were measured in picograms and expression values were standardized to control values from $18 \mathrm{~S}$ rRNA primers. Statistical analysis was done using one way ANOVA and Tukey's post hoc test on GraphPad.

Transfection assays For transfection assays, cells were plated at a density of 25,000 cells/well in a 24 well plate. Cells were allowed to grow for $24 \mathrm{~h}$ at $37^{\circ} \mathrm{C}, 5 \% \mathrm{CO}_{2}$. Cells were then transfected with polyfect (Qiagen) as described by the manufacturer. Cells were transfected with plasmids containing a CCN2 promoter fused to a secreted alkaline phosphatase (SEAP) reporter gene. Cells were transfected with $1 \mu \mathrm{g}$ of CCN2-SEAP constructs that contained the -805 to +17 region of the CCN2 promoter (Abraham et al. 2000; Holmes et al 2001). Cells were cultured for $16 \mathrm{~h}$ in serum-free media then treated with or without wnts for $24 \mathrm{~h}$. To control for transfection efficiency cells were cotransfected with $0.5 \mu \mathrm{g}$ of a cytomegalovirus $(\mathrm{CMV})$ promoter- $\beta$-galactosidase $(\beta$-gal) reporter gene (Clontech, Palo Alto, CA, USA) construct. Promoter assays were performed with a Phospha-Light kit (Applied Bio- systems, Foster City, CA, USA) according to manufacturer's protocol and SEAP reporter expression was adjusted for differences in $\beta$-galactosidase expression as determined by a Galacto-Star kit (Applied Biosystems) according to manufacturer's protocol. Data was expressed as average values \pm standard deviation of at least three replicates and at least two independent trials. Measurement of SEAP levels

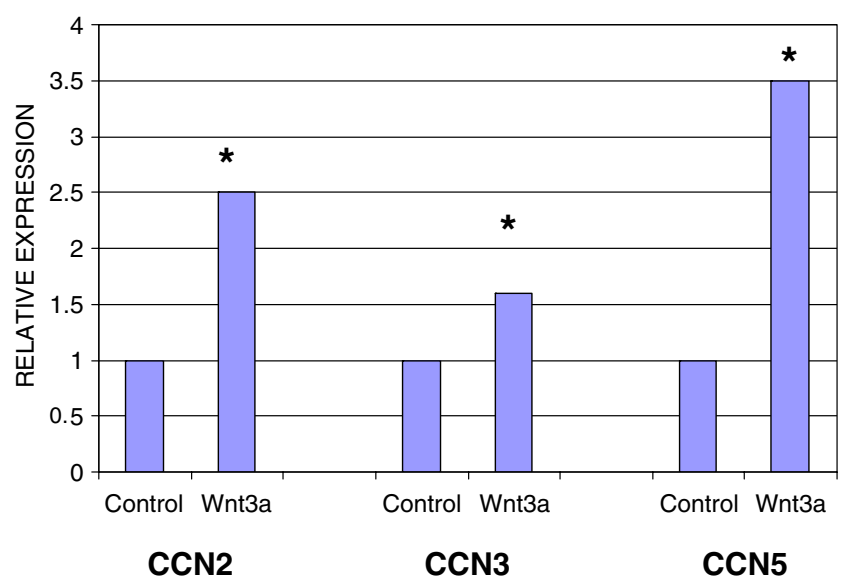

Fig. 3 Wnt $3 \mathrm{a}$ induces $\mathrm{CCN} 2, \mathrm{CCN} 5$ and $\mathrm{CCN} 3$ mRNAs. NIH $3 \mathrm{~T} 3$ fibroblasts were treated with or without Wnt3a $(150 \mathrm{ng} / \mathrm{ml})$ for the time periods as indicated. RNAs were harvested, and subjected to real time PCR analysis to detect 18S rRNA and target RNAs as indicated. Experiments were performed twice. A representative experiment is shown (three replicates). $\mathrm{CCN} 2, \mathrm{CCN} 5$ and $\mathrm{CCN} 3$ transcripts were examined. Note that Wnt3a was less effective at inducing CCN3 mRNA than at inducing CCN2 and CCN5 mRNAs. Variation within samples was less than $10 \%$ 

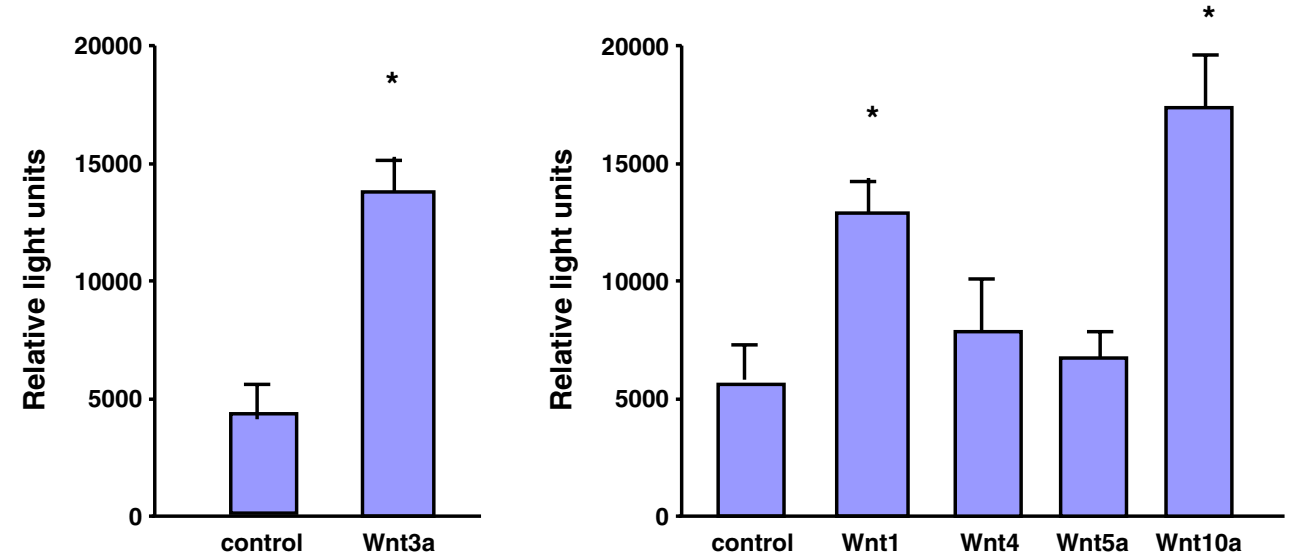

Fig. 4 Wnts 1, 3a and 10b, but not Wnts 4 or $5 \mathrm{a}$, induce the CCN2 promoter in fibroblasts. NIH $3 \mathrm{~T} 3$ fibroblasts were transfected with a $\mathrm{CCN} 2$ promoter/SEAP reporter construct, which contains the region spanning from -805 to +17 of the CCN2 promoter (Abraham et al. 2000). After a serum starvation step, cells were treated with or without

Wnt3a $(150 \mathrm{ng} / \mathrm{ml}, 24 \mathrm{~h})$ or with or without conditioned media from cells stably transfected with empty expression vector or expression vector encoding Wnt $1,4,5 \mathrm{a}$ or $10 \mathrm{~b}(24 \mathrm{~h})$. Experiments were performed thrice. A representative experiment is shown $(N=6$, average \pm standard deviation is shown). Significance is indicated by an asterisk

were obtained from an LMax II 384 luminometer (Molecular Devices, Sunnyvale CA, USA) and SoftMax Pro 4.7.1 (Molecular Devices, Sunnyvale CA, USA). Levels were measured in relative light units and were standardized to control values from $\beta$-gal. Statistical tests were done using one-way ANOVA and Tukey's post hoc test on GraphPad.

\section{Results}

mRNAs whose expression are altered by exposure of NIH 3 T3 fibroblasts to Wnt3a

To determine the effect of Wnts on fibroblasts, NIH 3T3 fibroblasts were incubated in serum-free media for $24 \mathrm{~h}$ and exposed to Wnt3a $(150 \mathrm{ng} / \mathrm{ml})$ for 6 hours. RNAs were extracted and subjected to Affymetrix genome-wide profiling. There were 145 genes induced greater that twofold by Wnt3a. Cluster analysis revealed that genes induced upon Wnt treatment included those mediating angiogenesis, Wnt signaling, cell adhesion and motility, cell proliferation and the cytoskeleton (Table 1). These mRNAs include CCN1 and $\mathrm{CCN} 2$, as anticipated, but also those encoding potent pro-differentiation/angiogenic proteins such as TGF $\beta 2$, endothelin-1 (ET-1) and vascular endothelial growth factor, all of which are involved with tissue remodeling and repair (Leask and Abraham 2006; Shi-wen et al. 2004, 2006; Tonnesen et al. 2000). Conversely, exposure of NIH 3T3 fibroblasts to Wnt3a reduced expression of 159 mRNAs including those mediating skeletal development, cell death and endopeptidase (matrix metalloproteinase) activity (Table 2). These results suggest that Wnt exposure is promoting angio- genesis at the expense of bone formation, and matrix production and remodeling at the expense of matrix degradation.

To further investigate the role of Wnt3a in the induction of gene expression in fibroblasts, we verified our gene expression profiling data using real-time PCR. We showed that a $6 \mathrm{~h}$ treatment of fibroblasts with Wnt3a resulted in an induction of CCN2, ET-1, TGF $\beta 2$ and VEGF-C mRNAs (Fig. 1). Based on these data, we also investigated whether Wnt3a could also induce additional genes involved with tissue remodeling and repair such as PLOD2 and thrombospondin-1 (van der Slot et al. 2003; Murphy-Ullrich and Poczatek 2000). To extend our results to other members of the Wnt family, we exposed fibroblasts to Wnt10b for 6 hours. Wnt $10 \mathrm{~b}$ induced a similar set of mRNAs to Wnt3a, although Wnt10b was not able to significantly induce VEGF-C (Fig. 1). To further analyze the ability of Wnts to induce gene expression in fibroblasts, fibroblasts were exposed in the presence or absence of Wnt3a for up to $48 \mathrm{~h}$. RNA was prepared and subjected to real-time PCR analysis using appropriate primers. These mRNAs were induced with slightly differing kinetics, but were nonetheless sustained over a $48 \mathrm{~h}$ period (Fig. 2).

\section{Wnt3a induces CCN2 (CTGF) and CCN5}

(Wisp2) and CCN3 (nov) mRNA expression in NIH $3 \mathrm{~T} 3$ fibroblasts

Our microarray analysis revealed, as expected, that $\mathrm{CCN}$ family members were induced upon Wnt3a treatment (Table 1). Of this family, CCN1, CCN2, CCN4 and CCN5 but not $\mathrm{CCN} 3$ (nov) mRNAs were detected as being increased upon Wnt3a treatment (Table 1). Real time PCR analysis confirmed that $\mathrm{CCN} 2$ and $\mathrm{CCN} 5$ were potently 
induced by Wnt3a, conversely CCN3 (nov) was induced approximately $50 \%$ (Fig. 3). These results confirm our microarray studies and indicate that $\mathrm{CCN} 3$ is not a potent responder to Wnt3a in fibroblasts.

Wnts $1,3 \mathrm{a}$ and $10 \mathrm{~b}$, but not Wnt 4 and $5 \mathrm{a}$, induce the CCN2 promoter in NIH 3 T3 fibroblasts

Our Affymetrix gene profiling and real-time PCR analysis confirmed previous results that Wnt3a induced CCN2 mRNA and protein in mesenchymal cells (Luo et al. 2004). For our studies, we considered that CCN2 was a key target of Wnt signaling because of the role of $\mathrm{CCN} 2$ as a key marker and mediator of wound healing and fibrogenesis (Blom et al. 2002; Leask and Abraham 2006). Accordingly, to obtain insights into the mechanism underlying Wnt action on fibroblasts, we investigated whether (a) the canonical Wnts (Wnt3a and 10b) could induce the CCN2 promoter. To perform this analysis, we transfected NIH 3T3 fibroblasts with a CCN2 promoter/reporter construct bearing nucleotides -805 and +17 of the promoter (Abraham et al. 2000; Leask et al. 2003) and exposed these cells to Wnts $3 \mathrm{~b}$ and $10 \mathrm{a}$. Wnts induced the CCN2 promoter (Fig. 4). To further assess the mechanisms by which Wnts act on the CCN2 promoter, we addressed whether additional Wnts could induce the CCN2 promoter. We found that an additional canonical Wnt, Wnt1, induced the CCN2 promoter (Fig. 4). Conversely, non-canonical Wnts 4 and 5a (Kuhl et al. 2000) were not able to induce the CCN2 promoter. These data extend the notion that Wnts regulate the CCN family, and in particular CCN2, in fibroblasts.

\section{Discussion}

Previous studies have found that Wnts are induced during tissue remodeling and repair (Okuse et al. 2005). However, the direct effect of Wnts on gene expression in fibroblasts has not been ascertained until this report. Wnt addition caused the induction of known Wnt targets such as members of the CCN family (Luo et al. 2004; Si et al. 2006). That Wnts induced CCN1, CCN2, CCN4 and CCN5 are not surprising as these are known Wnt targets (Luo et al. 2004; Si et al. 2006; Leask and Abraham 2006). Canonical, but not non-canonical, Wnts activate the $\mathrm{CCN} 2$ promoter; the mechanism underlying this activation is beyond the scope of our current paper. However, it in interesting that Wnt3a only modestly induced CCN3 (nov) mRNA. In this regard, CCN3 was recently shown to inhibit Wnt signaling (Rydziel et al. 2007) and thus that the lower magnitude of $\mathrm{CCN} 3$ induction by Wnt3a may be expected.

Fibrotic fibroblasts have been considered to have a 'Wnt signature' as revealed by cluster analysis of Affymetrix gene profiling data (Gardner et al. 2006). However, Wnt 3a did not cause an as potent induction of other profibrotic/ matrix remodeling genes as, say, application of TGF $\beta$ or ET-1 to fibroblasts (Shi-wen et al. 2004, Liu et al. 2007; Leask and Abraham 2004). For example, $\alpha$-smooth muscle actin ( $\alpha$-SMA) was not detected in our studies. However, in our current report we found that Wnt3a also induced mRNA expression of TGF $\beta 2$ and ET-1 (and indeed CCN2). We are currently evaluating if the Wnt cascade can induce excessive tissue remodeling/repair or fibrogenesis through these intermediaries.

It is interesting to note that Wnts enhanced the expression of angiogenenic and matrix remodeling genes at the expense of genes involved with skeletal development and in particular chondrogenesis (e.g. sox9). Previous evidence has suggested that Wnts induce an osteogenic lineage (in fact via CCN 1; Baron et al. 2006; Si et al. 2006). However, prior to initiating the osteogenic lineage, chondrogenesis is required, for which the sox9 is essential (Akiyama et al. 2005). Our results are therefore in good agreement with recent data that physical and functional interactions exist between $\beta$-catenin and Sox9. In vivo, either overexpression of $\operatorname{Sox} 9$ or inactivation of $\beta$-catenin in chondrocytes of mouse embryos produces a similar phenotype of dwarfism with decreased chondrocyte proliferation, delayed hypertrophic chondrocyte differentiation, and endochondral bone formation (Akiyama et al. 2004). Moreover, Sox 9 inhibits activation of $\beta$-catenin-dependent promoters and stimulates degradation of $\beta$-catenin (Akiyama et al. 2004), suggesting that chondrogenesis is controlled by interactions between Sox 9 and the $\mathrm{Wnt} / \beta$ catenin signaling pathway. Moreover, it is also intriguing that Wnt3a induced pro-mitotic mRNAs yet suppressed pro-apoptotic mRNAs. These results are consistent with recent observations that Wnt3a promotes proliferation of mesenchymal stem cells (Baksh and Tuan 2007). Collectively, our data support the notion that Wnts are potent modulators of fibroblast differentiation.

Acknowledgement Our work is supported by grants from the Canadian Institutes of Health Research (CIHR) and the Canadian Foundation for Innovation. A.L. is a New Investigator of the Arthritis Society (Scleroderma Society of Ontario) and a recipient of an Early Researcher Award. We are supported from funds received from the CIHR through the Canada Scleroderma Research Group (CSRG) New Emerging Team.

\section{References}

Abraham DJ, Shiwen X, Black CM, Sa S, Xu Y, Leask A (2000) Tumor necrosis factor alpha suppresses the induction of connective tissue growth factor by transforming growth factorbeta in normal and scleroderma fibroblasts. J Biol Chem 275: $15220-15225$ 
Akiyama H, Lyons JP, Mori-Akiyama Y, Yang X, Zhang R, Zhang Z, Deng JM, Taketo MM, Nakamura T, Behringer RR, McCrea PD, de Crombrugghe B (2004) Interactions between Sox9 and betacatenin control chondrocyte differentiation. Genes Dev 18:10721087

Akiyama H, Kim JE, Nakashima K, Balmes G, Iwai N, Deng JM, Zhang Z, Martin JF, Behringer RR, Nakamura T, de Crombrugghe B (2005) Osteo-chondroprogenitor cells are derived from Sox 9 expressing precursors. Proc Natl Acad Sci U S A 102:14665-14670

Baksh D, Tuan RS (2007) Canonical and non-canonical Wnts differentially affect the development potential of primary isolate of human bone marrow mesenchymal stem cells. J Cell Physiol 212:817-826

Baron R, Rawadi G, Roman-Roman S (2006) Wnt signaling: a key regulator of bone mass. Curr Top Dev Biol 76:103-127

Blom IE, Goldschmeding R, Leask A (2002) Gene regulation of connective tissue growth factor: new targets for antifibrotic therapy? Matrix Biol 21:473-482

Cadigan KM, Liu YI (2006) Wnt signaling: complexity at the surface. J Cell Sci 119:395-402

Chilosi M, Poletti V, Zamo A, Lestani M, Montagna L, Picolli P, Pedron S, Bertaso M, Scarpa A, Murer B, Cancellieri A, Maestro R, Semenzato S, Doglioni C (2003) Aberrant Wnt/beta-catenin pathway in idiopathic pulmonary fibrosis. Am J Pathol 162:1495-1502

Gardner H, Shearstone JR, Bandaru R, Crowell T, Lynes M, Trojanowska M, Pannu J, Smith E, Jablonska S, Blaszczyk M, Tan FK, Mayes MD (2006) Gene profiling of scleroderma skin reveals robust signatures of disease that are imperfectly reflected in the transcript profiles of explanted fibroblasts. Arthritis Rheum 54:1961-1973

Holmes A, Abraham DJ, Sa S, Shiwen X, Black CM, Leask A (2001) CTGF and SMADs, maintenance of scleroderma phenotype is independent of SMAD signaling. J Biol Chem. 276:10594-10601

Kennedy L, Liu S, Shi-Wen X, Chen Y, Eastwood M, Carter DE, Lyons KM, Black CM, Abraham DJ, Leask A (2007) CCN2 is necessary for the function of mouse embryonic fibroblasts. Exp Cell Res 313:952-964

Kühl M, Sheldahl LC, Park M, Miller JR, Moon RT (2000) The Wnt/ $\mathrm{Ca} 2+$ pathway: a new vertebrate Wnt signaling pathway takes shape. Trends Genet 16:279-283

Labbe E, Lock L, Letamendia A, Gorska AE, Gryfe R, Gallinger S, Moses HL, Attisano L Transcriptional cooperation between the transforming growth factor-beta and Wnt pathways in mammary and intestinal tumorigenesis. Cancer Res 67:75-78

Leask A, Abraham DJ (2004) TGF-beta signaling and the fibrotic response. FASEB J 18:816-827

Leask A, Abraham DJ (2006) All in the CCN family: essential matricellular signaling modulators emerge from the bunker. J Cell Sci 119:4803-4810

Leask A, Holmes A, Black CM, Abraham DJ (2003) Connective tissue growth factor gene regulation. Requirements for its induction by transforming growth factor-beta 2 in fibroblasts. J Biol Chem 278:13008-13015
Liu S, Xu SW, Kennedy L, Pala D, Chen Y, Eastwood M, Carter DE, Black CM, Abraham DJ, Leask A (2007) FAK is required for TGFbeta-induced JNK phosphorylation in fibroblasts: implications for acquisition of a matrix-remodeling phenotype. Mol Biol Cell 18:2169-2178

Logan CY, Nusse R (2004) The Wnt signaling pathway in development and disease. Annu Rev Cell Dev Biol 20:781-810

Luo Q, Kang Q, Si W, Jiang W, Park JK, Peng Y, Li X, Luu HH, Luo J, Montag AG, Haydon RC, He TC (2004) Connective tissue growth factor (CTGF) is regulated by Wnt and bone morphogenetic proteins signaling in osteoblast differentiation of mesenchymal stem cells. J Biol Chem 279:55958-55968

Morrisey EE (2003) Wnt signaling and pulmonary fibrosis. Am J Pathol 162:1393-1397

Murphy-Ullrich JE, Poczatek M (2000) Activation of latent TGF-beta by thrombospondin-1: mechanisms and physiology. Cytokine Growth Factor Rev 11:59-69

Musgrove EA (2004) Wnt signalling via the epidermal growth factor receptor: a role in breast cancer. Breast Cancer Res 6:65-68

Okuse T, Chiba T, Katsuumi I, Imai K (2005) Differential expression and localization of WNTs in an animal model of skin wound healing. Wound Repair Regen 13:491-497

Rydziel S, Stadmeyer L, Zanotti S, Durant D, Smerdel-Ramoya A, Canalis E (2007) Nephroblastoma overexpressed (Nov) inhibits osteoblastogenesis and causes osteopenia. J Biol Chem 282: 19762-19772

Schohl A, Fagotto F (2002) Beta-catenin, MAPK and Smad signaling during early Xenopus development. Development 129:37-52

Shi-wen X, Howat SL, Renzoni EA, Holmes A, Pearson JD, Dashwood MR, Bou-Gharios G, Denton CP, du Bois RM, Black CM, Leask A, Abraham DJ (2004) Endothelin-1 induces expression of matrix-associated genes in lung fibroblasts through MEK/ERK. J Biol Chem 279:23098-23103

Shi-wen X, Stanton LA, Kennedy L, Pala D, Chen Y, Howat SL, Renzoni EA, Carter DE, Bou-Gharios G, Stratton RJ, Pearson JD, Beier F, Lyons KM, Black CM, Abraham DJ, Leask A (2006) CCN2 is necessary for adhesive responses to transforming growth factor-betal in embryonic fibroblasts. J Biol Chem 281: 10715-10726

Si W, Kang Q, Luu HH, Park JK, Luo Q, Song WX, Jiang W, Luo X, Li X, Yin H, Montag AG, Haydon RC, He TC (2006) CCN1/ Cyr61 is regulated by the canonical Wnt signal and plays an important role in Wnt3A-induced osteoblast differentiation of mesenchymal stem cells. Mol Cell Biol 26:2955-2964

Tonnesen MG, Feng X, Clark RA (2000) Angiogenesis in wound healing. J Investig Dermatol Symp Proc 5:40-46

van der Slot AJ, Zuurmond AM, Bardoel AF, Wijmenga C, Pruijs HE, Sillence DO, Brinckmann J, Abraham DJ, Black CM, Verzijl N, DeGroot J, Hanemaaijer R, TeKoppele JM, Huizinga TW, Bank RA (2003) Identification of PLOD2 as telopeptide lysyl hydroxylase, an important enzyme in fibrosis. J Biol Chem 278: 40967-40972

Willert K, Jones KA (2006) Wnt signaling: is the party in the nucleus? Genes Dev 20:1394-1404 